total quantity of arsenic I could obtain by simply boiling in acidulated water. This amounted to about 4 grains. Thus a total of 6.5 grains of arsenic was obtained by analysis.

At the very time Mr. Humphreys was holding the inquest on the above child, he was called upon to institute an inquiry into the cause of the death of another infant who succumbed under similar circumstances. The deceased was attended by Dr. Mallam, of Hackney Wick. The child (a female) was born on June 11th. The violet powder was employed as usual. Within a short time of the application the skin became red, and vomiting and purging set in, which continued until death. Dr. Mallam further reports "an inflammatory condition of the abdomen, groins, and armpits, with induration of the tissue about the navel."

Dr. Mallam, who had detected arsenic in the violet powder used in this case, forwarded me a sample which on analysis gave the following results :-

$$
\begin{array}{lllllr}
\text { Arsenions acid ... } & \ldots & \ldots & \ldots & 38 \cdot 3 \\
\text { Starch _. } & \ldots & \ldots & \ldots & \ldots & 55 \cdot 4 \\
\text { Magnesia \&c. } & \ldots & \ldots & \ldots & \ldots & 6 \cdot 3 \\
& & & & & \frac{100 \cdot 0}{100}
\end{array}
$$

Death occurred on the fourteenth day (June 25 th).

Three days after death Dr. Phillips, of Spital-square, made a post-mortem examination, and reports as follows:"Body black and decomposed; funis not separated; the abdominal parietes very much thickened and adherent to the viscera, with here and there extensive deposits of lymph; rectum very inflamed; the kidneys and spleen very much congested, and the liver slightly congested."

(1) The stomach and intestines, (2) the spleen, (3) the liver, and (4) the kidneys, were forwarded to me for examination in separate jars. The stomach $I$ found intensely inflamed and studded all over with small petechial dots, this state being very characteristic in my experience of death by arsenic. The duodenum was also very congested, parts of the small intestines being similarly affected. On analysis $\mathrm{I}$ obtained the following results :-

(1) The stomach and intestines yielded distinct traces of arsenic.

(2) The spleen yielded two grains of arsenic.

(3) The liver yielded about one grain of arsenic.

(4) In the kidney I detected. small but distinct traces of its presence.

In this case, therefore, I extracted upwards of three grains of arsenic from the viscera examined.

There are, in conclusion, one or two remarks I should wish to make on these two cases of poisoning (as we are bound to regard them) from the external application of arsenic, and which we have good cause to fear are only two of very many deaths that have resulted from this deplorable, although perfectly accidental, mistake.

1. It is to be noted that in both cases the bodies decomposed rapidly after death. The weather, it is true, was intensely hot at the time; but, apart from this, it is worth recording what I have noted elsewhere, and on another occasion, that when death results from the external application of arsenic the intense eruption consequent thereupon (in these cases described as resulting in actual sloughing of the skin) effects a more rapid, rather than a less rapid, decay. It is generally stated, and it accords with my own experience, that after death by the internal administration of arsenic putrefaction is slow. This rule has, however, its exceptions, and I know of more than one case where putrefaction seemed to be unusually rapid. Summarising these facts, I would say that "delay in putrefaction is an argument in favour of suspecting death from the internal administration of arsenic in suspicious cases, but that rapid putrefaction is in no respect to be considered a conclusive argument against it."

2. It is to be noted that in the first case I have recorded the analysis was not commenced until the infant had been dead for nineteen days, and had been buried for twelve days.

3. The quantity of arsenic found is surprising. I quite admit the force of the question put to me by the solicitor for the defence, whether it was not likely that some of the arsenic found was not derived from the surface of the skin, and got mixed up with the viscera during the post-mortem examination? I admit the possibility, but not the probability.

4. By what means did the arsenic get into the body? That the poison may be absorbed by the sound skin there is abundance of evidence to prove. The absorption, moreover, was, no doubt, rendered infinitely more rapid when the skin became irritated and ulcerated so as to expose open surfaces. But, in addition to these inlets, there can be very little question but that a certain quantity of arsenic must have been inhaled as the powder was being dusted on the body with the common powder-puff, and, moreover, that rectum and vagina (for both these children were female children) aided largely the work of carrying the poison into the general system.

5. Lastly, we may ask, why are these compounds used at all? Thirty-five per cent. of sulphate of lime (for this is admittedly a common adulterant, and for which, in this case, the arsenic was, possibly, substituted) is not an advisable preparation for the nursery. I fear, too often, the use of violet powder is an excuse for want of cleanliness; but, admitting its use (although to a far less extent than is common, for it is only needed in the folds of the skin, and not over the entire surface of the body), ordinary fullers' earth, or, what is even better, common starch-powder pure and simple, perfumed with a few drops of eau-de-cologne (a little scent being a necessity), is all that is wanted, and is infinitely preferable to the numerous concocted preparations for the toilet met with in the shops.

Queen Anne-street, Cavendish-square, w.

CASE OF

\section{DISLOCATION OF THE RIGHT HIP INTO} THE ISCHIATIC NOTCH.

\section{BY SURGEON-MAJOR J. E. MOFFATT.}

IN January, 1871, when in temporary medical charge of the employés of the East Indian Railway at Cawnpore, I was summoned to attend a pointsman who had been run over by a carriage he had been assisting to shunt. On my arrival at the railway station, three hours after the accident, I found a tall, muscular native, of middle age, lying on his back on a bed in the dispensary, without a scratch or bruise visible upon him, but complaining of pain in the right hip and of inability to move the leg of that side. The leg was slightly flexed at the knee, and the whole limb rotated in wards. The toes overlapped those of the other foot. The head of the femur could not be felt. The great trochanter was less prominent than the other, and there was half an inch of shortening.

A brief examination sufficed to satisfy me that there was no fracture of the femur or acetabulum as far as I could make out, and that I had to deal with a simple dislocation of the head of the femur backwards and into the ischiatic notch. The particulars of the accident then elicited from the patient confirmed this diagnosis. He informed me that he and four others were fetching an empty first-class carriage from a siding to be attached to the down train to Calcutta then waiting in the station. He and one man were walking upon the rails, pulling, and three were behind pushing up the empty carriage. As he was walking at a smart pace on the rail next the platform, he stumbled and fell forward upon his face and hands. With great pre. sence of mind he instantly rolled over upon his back into the space between the rail and the platform. The impetus. of the carriage was such that the men were unable to check it until nearly half its length had passed over the man on the ground. Unfortunately, in rolling over, he flung himself too far, so that he lay somewhat upon his left side and not fairly upon his back, his head being in the same direction as the carriage was going, and he somehow failed to stretch out his legs. Be that as it may, the lower foot-board caught his right knee just at and below the patella, and pulled the leg and thigh upwards and inwards across the abdomen, in which attitude he was found, and when extricated was so firmly jammed that the carriage had to be lifted up with screw-jacks.

I immediately proceeded to place the patient under chloroform, employing extension and counter-extension in the usual manner, and, clasping my hands round the thigh as high as possible, I pulled outwards to keep the head of the femur clear of the acetabulum. Barely one minute had elapsed before the head of the femur returned to its normal 
position with a snap, audible to me and sensible to the men making extension. I contented myself then with tying the man's feet together, and he recovered perfectly without a single drawback, and was at his work as well as ever in two weeks.

The clear and intelligible account of this accident, given above, was fully and independently corroborated by the European officials, who informed me afterwards that they found the man in the space between the platform and the wheels, that his right leg was bent upon and acruss his belly, and that it was kept in that position by the under surface of the lower foot-board, until the carriage was raised, after which he had no power in it. The height of the footboard from the ground was nineteen inches. This case of backward dislocation of the hip would have remained in oblivion but for the appearance in ThE LANCET of Feb. 17th, 1877, of a paper upon "Dislocations of the Thigh," read by Mr. Henry Morris before the Medical and Chirurgical Society, on seeing which this case recurred to me as leading to different conclusions from some of those arrived at by that gentleman-namely, conclusions 4,5 , and 11 .

No. 4 asserts that all dislocations of the thigh, unaccompanied by fracture, occur while the limb is abducted. Now, in the above-noted case there was certainly no fracture of the femur nor acetabulum, as evidenced by the speedy recovery without apparatus, and the absence of deformity; and as to the position of the limb during the accident abduction was simply impossible. The facts of the case and the evidence lead irresistibly to the conclusion that it was in a state of flexion and adduction.

No. 5 asserts that posterior dislocations result when flexion and inward rotation accompany abduction. With regard to this statement, I think there could have been no rotation once the knee was caught by the foot-board, and therefore rotation of the limb on its axis must be excluded as an essential element of backward dislocation.

No. 11 asserts that direct dorsal dislocations, or those which are said to occur during adduction, are always the result of immense violence, and are always associated with fracture of the acetabulum, or of the head of the femur, or of both. Now in this case, while there was enormous force applied to the tibial end of the femur, while that bone was being flexed and adducted on a fixed pelvis, no fracture whatever occurred. I do not mean to convey that backward dislocations may not occur through inward rotation and abduction, but it must be conceded that such conditions are not essential, any more than is fracture of the neck of the femur or acetabulum.

Naini Tal, India.

CASE OF

\section{ABSENCE OF THE INTER-AURICULAR SEPTUM, WITHOUT CYANOSIS, IN} A MAN AGED FORTY.

By RICHARD CATON, M.D., M.R.C.P. LOND., HON. PHYSICIAN TO THE LIVERPOOL NORTHERN HOSPITAL.

WRITERS on heart disease have long been divided in opinion as to the causes of cyanosis. The fact that a patent foramen ovale or other abnormal communication between renous and arterial channels often coexists with that condition has naturally led to the view that it is due simply to the circulation of mixed arterial and venous blood. This appears indeed, at first sight, a most natural and sufficient explanation, and it has been adopted by many writers of eminence. Other authorities, again, among whom may be mentioned Laennec, Morgagni, Louis, Hall, Peacock, and more particularly Stille, explain cyanosis otherwise, the last-named writer especially contending that it may exist without any admixture of arterial and venous blood, and lso that complete admixture may occur without giving rise to cyanosis.

The following case is interesting as an example of the ast-named proposition. In the journals and in the Transuctions of various Societies I have met with numerous cases f open foramen ovale in the absence of cyanosis, the opening jeing in some few instances as large as a shilling. But the zase here narrated is more remarkable than any, for the auricles being much dilated, a disc three inches in diameter could be placed in the aperture between them without undue stretching.

August I aged forty, was admitted into the Liverpool Northern Hospital on Dec. 10th, 1877, suffering from dyspncea, œdema of legs, and ascites. Patient is a powerfully-built and muscular man, who has had good health all his life, excepting that three months ago he had an attack like the present one. He has been for twenty years at sea. A fortnight ago he caught a severe cold, which brought on a cough with profuse expectoration, and a week later was followed by dropsy. On admission, patient was somewhat cyanosed, and had much cough and expectoration. Pulse 50, intermittent and unequal; temperature $100^{\circ}$; arteries rigid; cardiac dulness greatly enlarged; sounds normal; veins on left side of neck dilated and pulsating synchronously, with cardiac diastole, and filling from below; lungs resonant on percussion; expiration prolonged; crepitation at both bases, and râles in nearly all other parts; alimentary system normal, excepting that the tongue is slightly furred; urine pale, acid, sp. gr. 1007, no albumen. The treatment consisted in milk diet, the use of a gentle expectorant mixture, and rest in bed. Under this he rapidly improved, cyanosis, cedema, and ascites entirely disappeared, and the râles and crepitation nearly so.

Towards the close of December he had a relapse; temperature went up to $102^{\circ} \mathrm{F}$., and he complained of sorethroat, headache, and pain in the back. A little albumen and a few granular casts appeared in the urine. There was also some return of cyanosis and of dyspncea. In a few days these symptoms again subsided, and he appeared quite well. He was free from cyanosis and dyspnoea; could walk with ease, and ascend the stairs to the top floor of the hospital with little difficulty. Cardiac dulness unaltered; pulse still slow and intermitting. Believing himself quite well, and being determined to return to work, he was discharged on the 18th of January, after being duly cautioned.

The patient was readmitted on the 29 th of January, much cyanosed and with great dyspnoea; lungs full of crepitation and râles. On the next day, while attempting to get out of bed, he fell dead on the floor.

Necropsy, twenty-four hours after death. -The pericardium was largely adherent; ventricles, auricles, and appendices were greatly dilated. The pulmonary artery was unusually large, as also were its branches throughout the lungs. All the valves were apparently healthy. No communication existed between the aorta and the pulmonary artery. There was no partition between the auricles; a small fold of endocardium showed the line of demarcation between them, and, as mentioned above, a disc of cardboard three inches in diameter just fitted the orifice. Nothing was noted of importance in the other organs.

Considering the extraordinary size of the aperture between the auricles, and the slow action of the heart, it looks almost as certain that the venous and arterial blood must have mixed as it is that milk and coffee do when poured into a coffee-cup, and yet, under ordinary circumstances, there was no cyanosis and no impairment of muscular and nervous activity.

Liverpool.

\section{EMBOLISM OF THE BRACHIAL ARTERY FOLLOWED BY GANGRENE OF THE HAND AND FOREARM.}

\section{BY RICHARD T. GORE, F.R.C.S.}

MRs. H_, living about twenty miles from Bath, had a miscarriage at the latter end of November, 1867. When partially recovered, though a uterine discharge still continued, she was exposed to extreme cold at night. Up to Dec. 10th, she had suffered for some days very severe pain in the left hand and forearm. On Dec. 16th, it was found that all pulse in the radial and ulnar arteries had ceased, and the former could be felt at the wrist as a solid cord. Paroxysms of severe pain continued for several days, especially about the elbow. Sensation remained perfect, and there was very little reduction of temperature until Dec. 26th. At that time all pulsation had ceased up to the middle of 